\title{
Percutaneous closure versus medical therapy for stroke with patent foramen Ovale: a systematic review and meta-analysis
}

\author{
Xin-Lin Zhang ${ }^{\dagger}$, Li-Na Kang $^{\dagger}$, Lian Wang and Biao Xu* (i)
}

\begin{abstract}
Background: Patent foramen ovale (PFO) closure has emerged as a secondary prevention option in patients with PFO and cryptogenic stroke. However, the comparative efficacy and safety of percutaneous closure and medical therapy in patients with cryptogenic stroke and PFO remain unclear.

Methods: Randomized controlled trials (RCTs) and comparative observational studies that compared PFO closure against medical therapy, each with a minimal of 20 patients in the closure arm and 1-year follow-up were included.

Results: We analyzed 6961 patients from 20 studies (5 RCTs and 15 observational studies) with a median follow-up of 3.1 years. Moderate-quality evidence showed that PFO closure was associated with a significantly lower incidence of the composite outcome of ischemic stroke, transient ischemic attack (TIA), or all-cause death (odds ratio [OR]: 0.57; 95\% confidence interval [Cl]: 0.38 to 0.85; $P=0.006$ ), mainly driven by lower incidence of stroke (OR: 0.39; $95 \%$ Cl: 0.24 to $0.63 ; P<0.001)$. The numbers needed to treat were 43 and 39 for the composite outcome and recurrent ischemic stroke respectively. PFO closure increased the risks for atrial fibrillation or atrial flutter (OR: 5.74; 95\% Cl: 3.08 to 10.70; $P<0.001$; high-quality evidence) and pulmonary embolism (OR: 3.03; $95 \% \mathrm{Cl}: 1.06$ to 8.63; $P=0.038$; moderate-quality evidence), with the numbers needed to harm being 30 and 143 respectively. The risks for TIA, all-cause death, and major bleeding were not statistically different. Analyses limited to RCTs showed similar findings, as did a series of other subgroup analyses.
\end{abstract}

Conclusion: In conclusion, PFO closure reduced the incidences of stroke and the composite outcome of ischemic stroke, TIA, or all-cause death, but increased risks for atrial fibrillation or atrial flutter and pulmonary embolism compared with medical therapy.

Keywords: Percutaneous closure, Medical therapy, Cryptogenic stroke, Patent foramen ovale, Meta-analysis

\section{Background}

Among the 800,000 ischemic strokes that occur in the United States each year, up to 30 to $40 \%$ have no undetermined cause and are termed as cryptogenic [1]. Patent foramen ovale (PFO) was presented in 15 to $25 \%$ of the general adult population, but the prevalence was 2 to 3 times higher in patients with cryptogenic stroke $[2,3]$. Paradoxical embolism via a PFO is one the potential causes of cryptogenic stroke in these patients $[1,4]$. PFO closure has, therefore, emerged as a

\footnotetext{
* Correspondence: xubiao62@nju.edu.cn

${ }^{\dagger}$ Equal contributors

Department of Cardiology, Affiliated Drum Tower Hospital, Nanjing University School of Medicine, 321 Zhongshan Road, Nanjing 210008, China
}

secondary prevention option in patients with PFO and cryptogenic stroke.

Three previously published randomized controlled trials (RCTs)-CLOSURE I (Evaluation of the STARFlex Septal Closure System in Patients with a Stroke and/or Transient Ischemic Attack due to Presumed Paradoxical Embolism) [5], PC (Percutaneous Closure of Patent Foramen Ovale in Cryptogenic Embolism) [6], and RESPECT (Randomized Evaluation of Recurrent Stroke Comparing PFO Closure to Established Current Standard of Care Treatment) trials [7] - all failed to show superiority of closure over medical therapy. They were insufficient to draw any conclusion because sample size of the study cohorts and event rates were lower than 
anticipated. A number of meta-analyses, almost all based on only these 3 RCTs, have yielded different conclusions, with some showing possible borderline benefits of closure and others showing no benefit depending on how to carry out the analysis [8-11]. The clinical benefits of PFO closure relative to medical therapy remain inconclusive. With new data recently reported from 2 additional RCTs and the extended follow-up data of the RESPECT trial, we performed an updated meta-analysis to offer a clearer picture of the efficacy and safety of PFO closure compared with medical therapy. We also included and provided separate analysis of comparative observational studies to complement findings from RCTs.

\section{Methods}

We reported the meta-analysis in accordance with the Preferred Reporting Items for Systematic Reviews and MetaAnalyses (PRISMA) statement (Additional file 1) [12].

\section{Data sources and searches}

We searched several electronic databases, including MEDLINE via PubMed, EMBASE, and the Cochrane Central Register of Controlled Trials from their inception to September 15, 2017, without imposing any language restriction. The following keywords and search terms were used: patent foramen ovale, PFO, stroke, closure, and occlude. We also manually checked reference lists of retrieved primary studies, relevant reviews and meta-analyses.

\section{Study selection}

Two reviewers (X.Z. and L.K.) independently screened titles and abstracts of identified studies. Full-text of each potentially relevant study was obtained for further assessment for inclusion. Discrepancies were resolved by consensus. To be included, studies had to be randomized controlled trials (RCTs) or comparative observational studies making head-to-head comparison of patent foramen ovale closure with medical therapy in patients with cryptogenic stroke. All studies had to report at least one outcome of interest, have a minimal of 20 patients in the device closure arm and 1-year follow-up.

\section{Outcome measures}

The primary outcome was the composite outcome of ischemic stroke, transient ischemic attack (TIA), or allcause death; some studies also included peripheral embolism in this composite outcome. Secondary endpoints included recurrent ischemic stroke, TIA, all-cause death, atrial fibrillation (AF) or atrial flutter, pulmonary embolism, major bleeding and any serious adverse events.

\section{Data extraction and quality assessment}

Two investigators independently extracted data from each study, which included the following items: study name, number of patients, follow-up duration, patient demographic and clinical data and outcome events. The same reviewers independently assessed the quality of each randomized trial according to the Cochrane Collaboration guideline [13] and each observational study with the Newcastle-Ottawa Scale [14]. Discrepancies were resolved through discussion and consensus.

\section{Grading of evidence}

Two reviewers graded the overall methodological quality of each pooled analysis using the Grading of Recommendations, Assessment, Development and Evaluation (GRADE) approach, which takes into account issues related to risk of bias, inconsistency, indirectness, imprecision, and publication bias. The quality of evidence was judged as high, moderate, low or very low, using GRADEpro version 3.6 (GRADEpro GDT).

\section{Data synthesis and statistical analysis}

We performed intention-to-treat analysis whenever possible. The longest follow-up data from individual trials were used. Odds ratios (OR) and their corresponding confidence intervals were calculated for each study and pooled with random- (DerSimonian-Laird method) or fixed- (Mantel-Haenszel method) effect models according to heterogeneity detected across studies [15]. Heterogeneity was analyzed by means of the $I^{2}$ statistic and the $\mathrm{X}^{2}$-based Q test [16]. The cut points were $I^{2}>50 \%$ or $\mathrm{P}$ of the $\mathrm{X}^{2}$ test $<0.1$. In case there was no outcome event in one of the treatment arms, the treatment arm continuity correction was applied [17]. Publication bias was assessed by visually inspecting the funnel plots and by performing Begg's and Egger's tests. To explore the robustness of our findings, we conducted a series of subgroup analyses based on the study design (RCT or observational study), number of patients ( $\geq 400$ patients or $<400$ patients) and duration of follow-up ( $\geq 3$ years or $<3$ years). The number needed to treat or number needed to harm was calculated from randomized trials for risk estimates where risk difference was significant, with the method from meta-analytical estimates but not treating the data as if it all arose from a single trial because the latter is susceptible to Simpson's paradox $[18,19]$. In randomized trials, several prespecified subgroup analyses were reported, which included gender (male or female), age ( $<45$ years or $\geq 45$ years), entry event (stroke or TIA), shunt size (large or small to moderate), and atrial septal aneurysm (present or absent at enrollment). We directly extracted and performed pooled analyses of these data. We also conducted metaregression analysis to estimate the effects of covariates, 
including percent of moderate to severe PFO, atrial septal aneurysm, index event of stroke, and anticoagulation in medical treatment, on major outcomes of interests. For the effect estimate, a 2-tailed $P$ value less than 0.05 was considered statistically significant. Data were analyzed with Stata 12.0 (StataCorp).

\section{Results}

\section{Study selection and characteristics}

We identified 1408 citations through database searching. After complete evaluation, 20 studies published in 21 articles were included in the final analysis (Additional file 2: Figure S1) [5-7, 20-37]. Five studies were RCTs $[5,6,20-22]$ and 15 were comparative observational studies [23-37]. A total of 6961 patients receiving device closure $(n=3375)$ or medical therapy $(n=3586)$ were included in the analysis. Sample size ranged from 92 to 980 , the mean age from 35.3 to 54.0 years, the proportion of male patients from $42.0 \%$ to $76.8 \%$, the median duration of follow-up from 1.2 to 9.0 years. The percent of index event of stroke ranged from $30 \%$ to $100 \%$, percent of atrial septal aneurysm from $7.1 \%$ to $51.7 \%$, percent of moderate to severe PFO from $10.5 \%$ to $100 \%$. Three studies [21-23] exclusively used antiplatelet therapy in the medical therapy group while others used antiplatelet or anticoagulation therapy or a combination of these two antithrombotic treatments. The percent of patients receiving anticoagulation therapy was mainly reported in randomized trials, ranging from 0 to $34.2 \%$. In most cases, closure patients received a mixed type of occlude devices, except those in 5 studies [6, 20, 25-27] that exclusively used Amplatzer PFO Occluder and those in 1 study [5] that exclusively used STARFlex Septal Closure System. Main baseline characteristics for each study are presented in Table 1. Other study characteristics are presented in Additional file 2: Table S1 to S3. The definitions of the composite outcome, major bleeding, recurrent stroke and TIA are presented in Additional file 2: Table S4.

In two studies [20,22], the method of random sequence generation was not reported, so they were judged as being of unclear risk of bias. Blinding of personnel and participants was not possible for all trials and thus was judged as high risk of bias. All trials had blinded outcome adjudication; and the risk for detection bias, attrition bias, reporting bias and other bias were generally low. All comparative observational studies scored well on patient selection and outcome, but only 3 controlled for important confounding factors [23-25]. Detailed quality assessment of the included studies is summarized in Additional file 2: Table S5 and S6).
Composite outcome ischemic stroke, TIA, or all-cause death Percutaneous closure was associated with significantly lower risk for the composite outcome of ischemic stroke, TIA, or death from any cause (OR: 0.57 ; $95 \%$ CI: 0.38 to $0.85 ; P=0.006)$ compared with medical therapy (Fig. 1). Limiting the analyses to RCTs, the results were similar (OR: 0.62 ; $95 \% \mathrm{CI}: 0.44$ to $0.88 ; P=0.007$ ); the number needed to treat was 43 . A statistically significant lower risk was also observed in observational studies (OR: 0.53; $95 \%$ CI: 0.29 to $0.97 ; P=0.040$ ), showing no significant difference with randomized trials ( $P$ value for interaction 0.90). Low and substantial heterogeneity was detected in randomized trials and observational studies respectively. Pooled analysis from 5 randomized trials and 3 adjusted observational studies showed very similar finding (OR: $0.64 ; 95 \% \mathrm{CI}: 0.49$ to $0.83 ; P=0.001$ ) (Additional file 2: Figure S2).

\section{Recurrent ischemic stroke}

Percutaneous closure significantly reduced the risk for recurrent ischemic stroke compared with medical therapy (OR: 0.39; 95\% CI: 0.24 to 0.63; $P<0.001$ ) (Fig. 2). Similar finding were found in randomized trials (OR: 0.41; $95 \%$ CI: 0.19 to $0.89 ; P=0.025$ ) and observational studies (OR: 0.36; $95 \%$ CI: 0.19 to $0.70 ; P=0.002$ ). The number needed to treat derived from randomized trials was 39 .

\section{Transient ischemic attack}

The overall incidences of TIA was not statistically different between device closure and medical therapy (OR: 0.72; 95\% CI: 0.44 to $1.18 ; P=0.193$ ) (Fig. 3). The lack of statistically significant difference was consistent in randomized trials (OR: $0.81 ; 95 \%$ CI: 0.56 to $1.17 ; P=0.253$ ) and observational studies (OR: $0.60 ; 95 \% \mathrm{CI}: 0.22$ to $1.64 ; P=0.322$ ).

\section{All-cause death}

Pooled all-cause mortality was similar between device closure and medical therapy (OR: 0.81; 95\% CI: 0.49 to $1.34 ; P=0.411$ ) (Fig. 4). Consistent findings were found in randomized trials (OR: $0.84 ; 95 \%$ CI: 0.40 to 1.74; $P=0.633$ ) and observational studies (OR: 0.78; 95\% CI: 0.49 to $1.34 ; P=0.847$ ).

\section{Atrial fibrillation or atrial flutter, and pulmonary embolism}

Pooled analysis from randomized trials showed that percutaneous closure significantly increased the risk for atrial fibrillation or atrial flutter (OR: 5.74; 95\% CI: 3.08 to $10.70 ; P<0.001$ ), and pulmonary embolism (OR: 3.03 ; $95 \% \mathrm{CI}: 1.06$ to $8.63 ; P=0.038)$ compared with medical therapy (Fig. 5a and b). The number needed to harm was 30 and 143 respectively. 


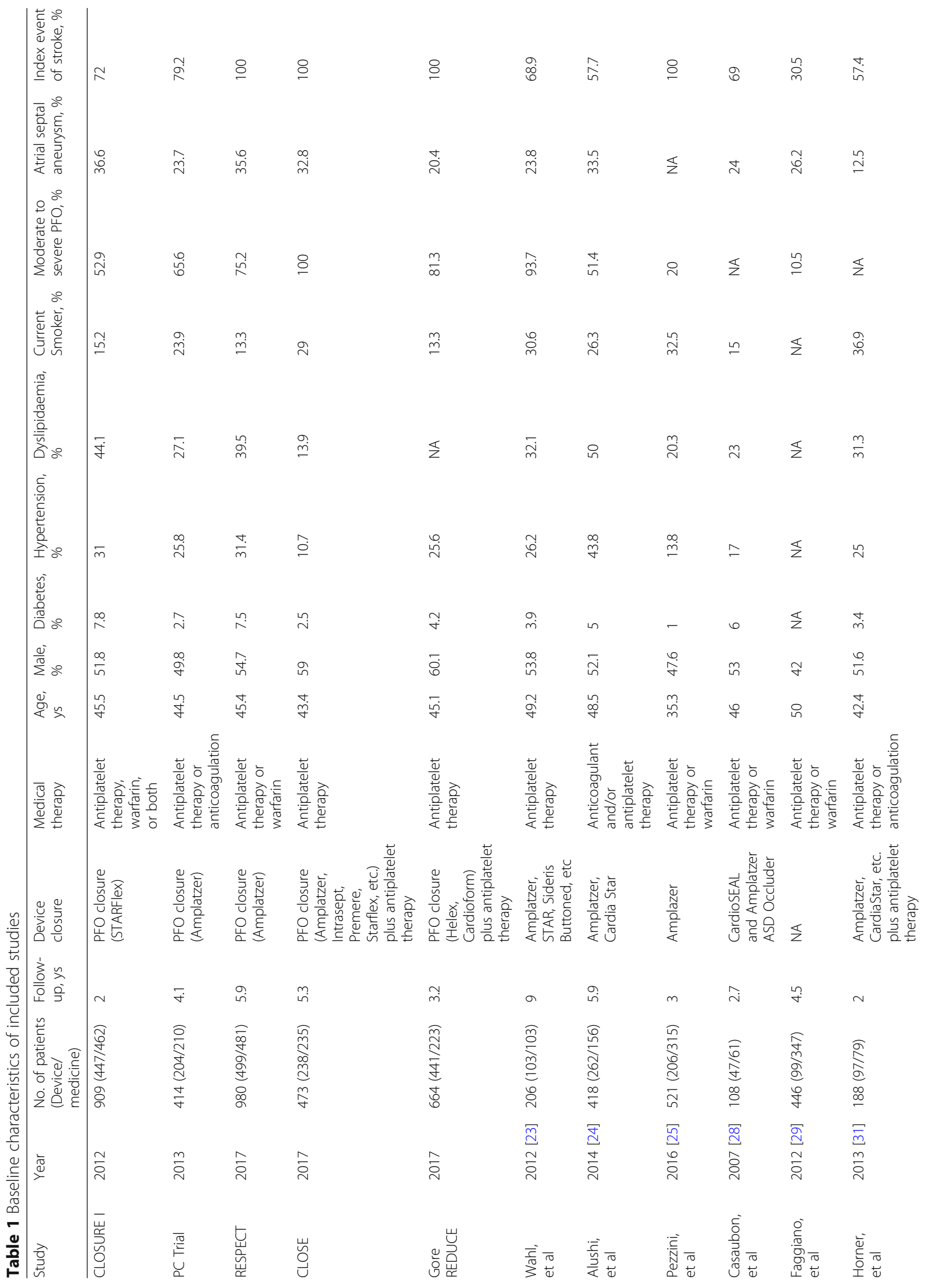




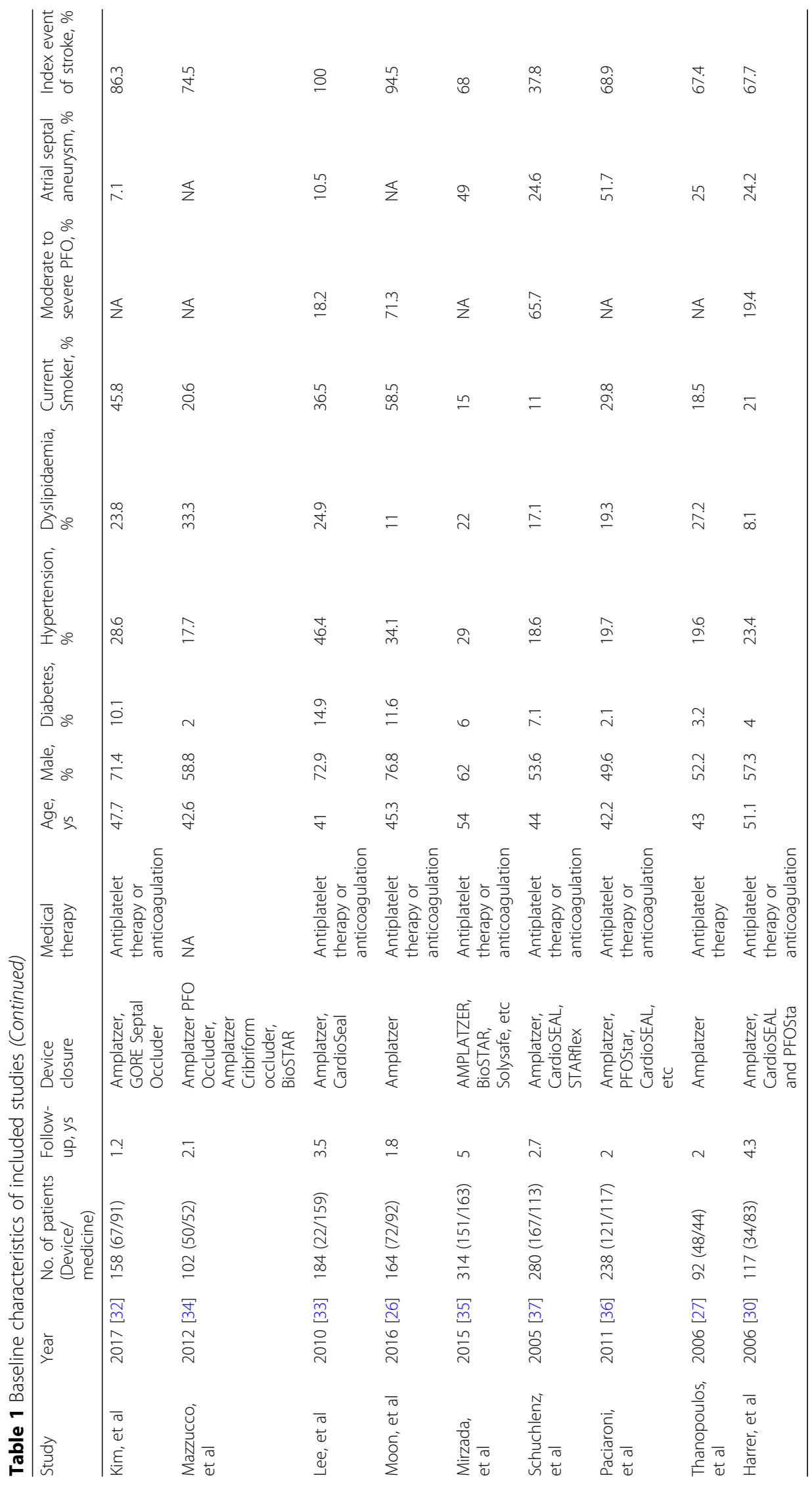




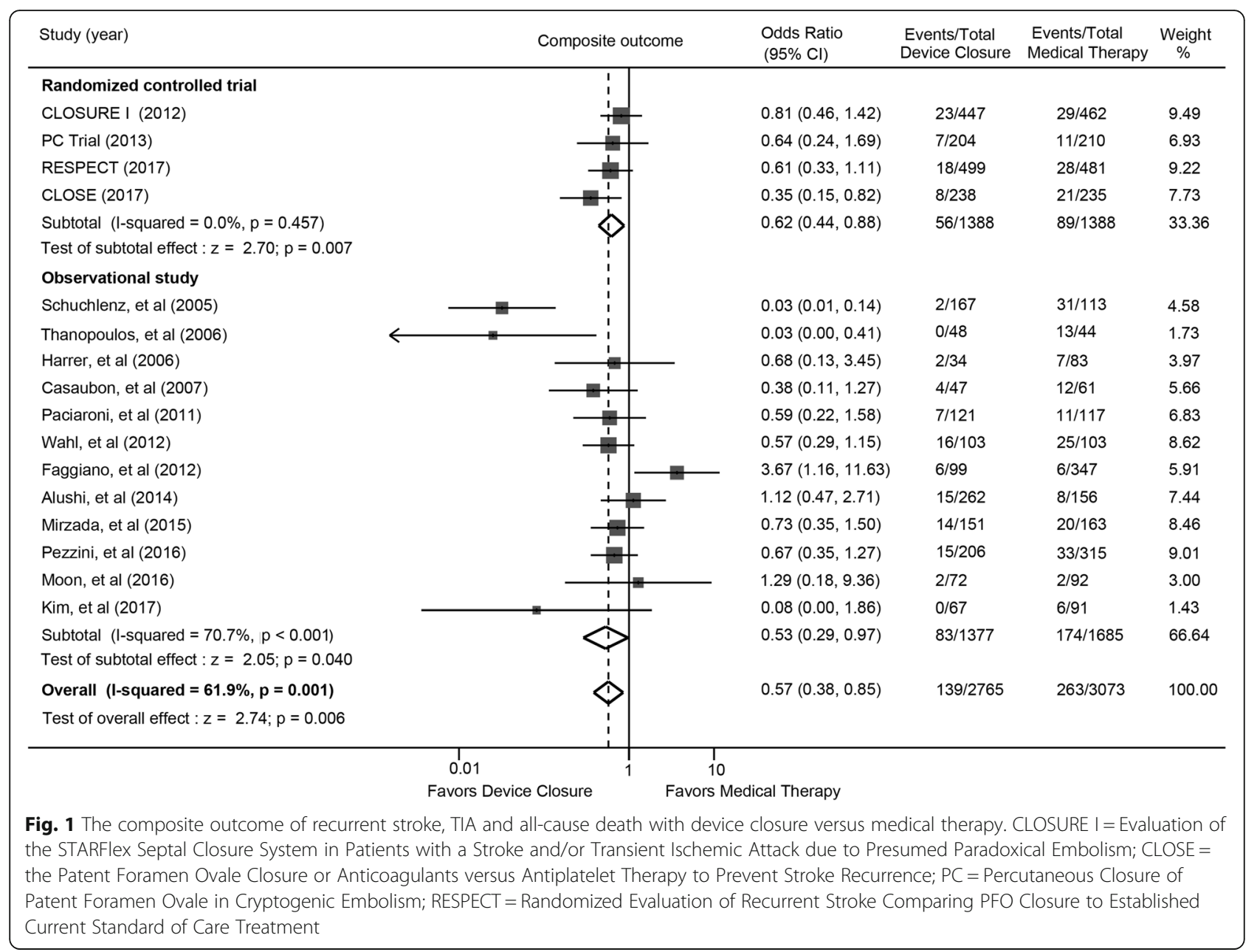

\section{Major bleeding, and any serious adverse events}

The incidences of major bleeding (OR: 1.01; 95\% CI: 0.55 to $1.86 ; P=0.967)$ and any serious adverse events (OR: $1.07 ; 95 \% \mathrm{CI}: 0.92$ to $1.25 ; P=0.387$ ) were similar between device closure and medical therapy (Fig. 5c and $\mathrm{d}$ ).

\section{Grading of evidence}

Based on GRADE summaries (Table 2), we deemed the quality of the evidence to be high for atrial fibrillation or atrial flutter, low for major bleeding, and moderate for other major outcomes. Reasons for rating down were provided in Table 2 .

\section{Major subgroup analysis}

We performed separate analysis for major outcomes stratified by study designs, number of patients and duration of follow-up. All tested summary effects, which included the composite outcomes, recurrent ischemic stroke, TIA and all-cause death, did not differ significantly in these stratified subgroups (Additional file 2: Table S7). We also performed pooled analyses of prespecified subgroup data from randomized trials, and found significantly lower incidence of the composite outcome only in patients with large shunt size, and lower incidence of recurrent stroke in patients with large shunt size and those present with atrial septal aneurysm, but no significant interaction was detected (Additional file 2: Table S8 and S9).

\section{Additional analyses}

There was no evidence of publication bias for all outcome assessment. Meta-regression did not detect significant confounding effect of the aforementioned covariates on all outcomes (Additional file 2: Table S10).

\section{Discussion}

Our analysis with data from 20 studies and 6961 patients, demonstrated that in patients with a PFO who had a cryptogenic ischemic stroke, PFO closure was associated with a significantly lower incidence of the composite outcome of ischemic stroke, TIA, or all-cause death as compared with medical therapy (moderatequality evidence), mainly driven by protection against 


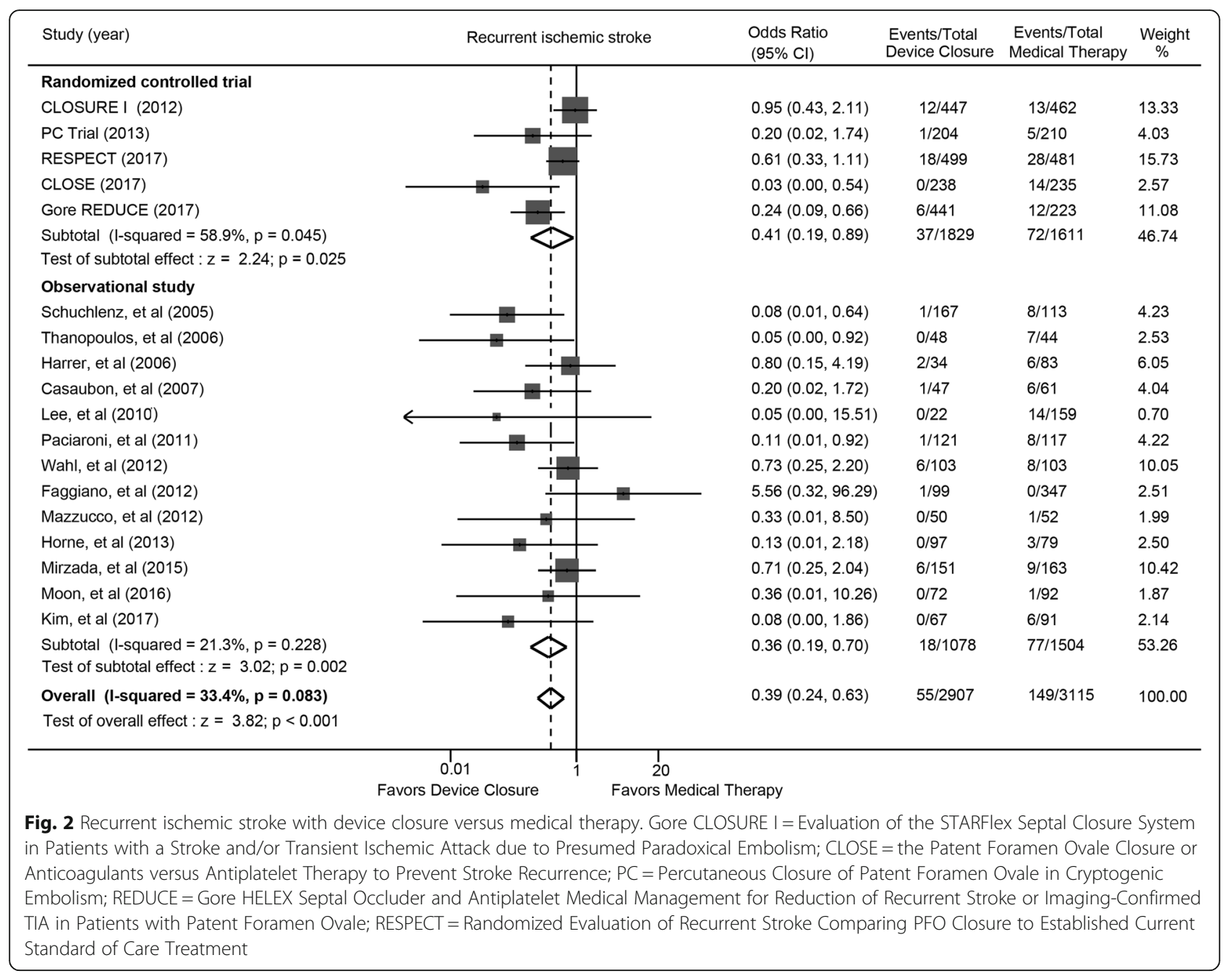

recurrent ischemic stroke. PFO closure increased the risks for atrial fibrillation or atrial flutter (high-quality evidence) and pulmonary embolism (moderate-quality evidence). The risks for TIA, all-cause death, major bleeding and any serious adverse events were not different. Analyses limited to RCTs closely mirrored these results, as did a series of subgroup analyses and metaregression analyses.

Several meta-analyses on this topic have been published, but all were pooled from 3 trials published in 2012 and 2013 [8-11]. These meta-analyses, with small-to-moderate sample size $(\sim 2300$ patient in total), were inadequately powered to draw conclusions on rare individual outcomes such as stroke. We included a number of recently published high-quality RCTs and observational studies, thus had a much larger sample size and an enhanced statistical power. A series of subgroup analyses with similar results supported the robustness of our findings. We also graded the quality of evidence using appropriate methodology (GRADE).
We showed that PFO closure might increase the likelihood of AF or atrial flutter (most was periprocedure), but the real burden of AF cannot be determined from our analysis because these included trials did not use continuous monitoring to monitor subclinical AF episodes. Subclinical episodes of AF were not uncommon and were associated with a significantly increased risk of stroke [38]. Also data about the autonomic function of the heart and heart rate variability was not reported, it would be interesting to have these data as autonomic dysfunction significantly contributed to silent AF [39]. Nevertheless, atrial fibrillation in our analysis seems not to increase the overall risk of stroke, as the overall risk for stroke was actually significantly reduced.

In the RESPECT trial, the benefit of PFO closure as compared with medical therapy was greater among patients receiving antiplatelet than anticoagulant therapy in the medical-therapy group [7, 20]. A meta-analysis with 8 studies also showed that anticoagulant therapy with warfarin might be superior to antiplatelet therapy in preventing recurrent stroke or TIA in patients with 


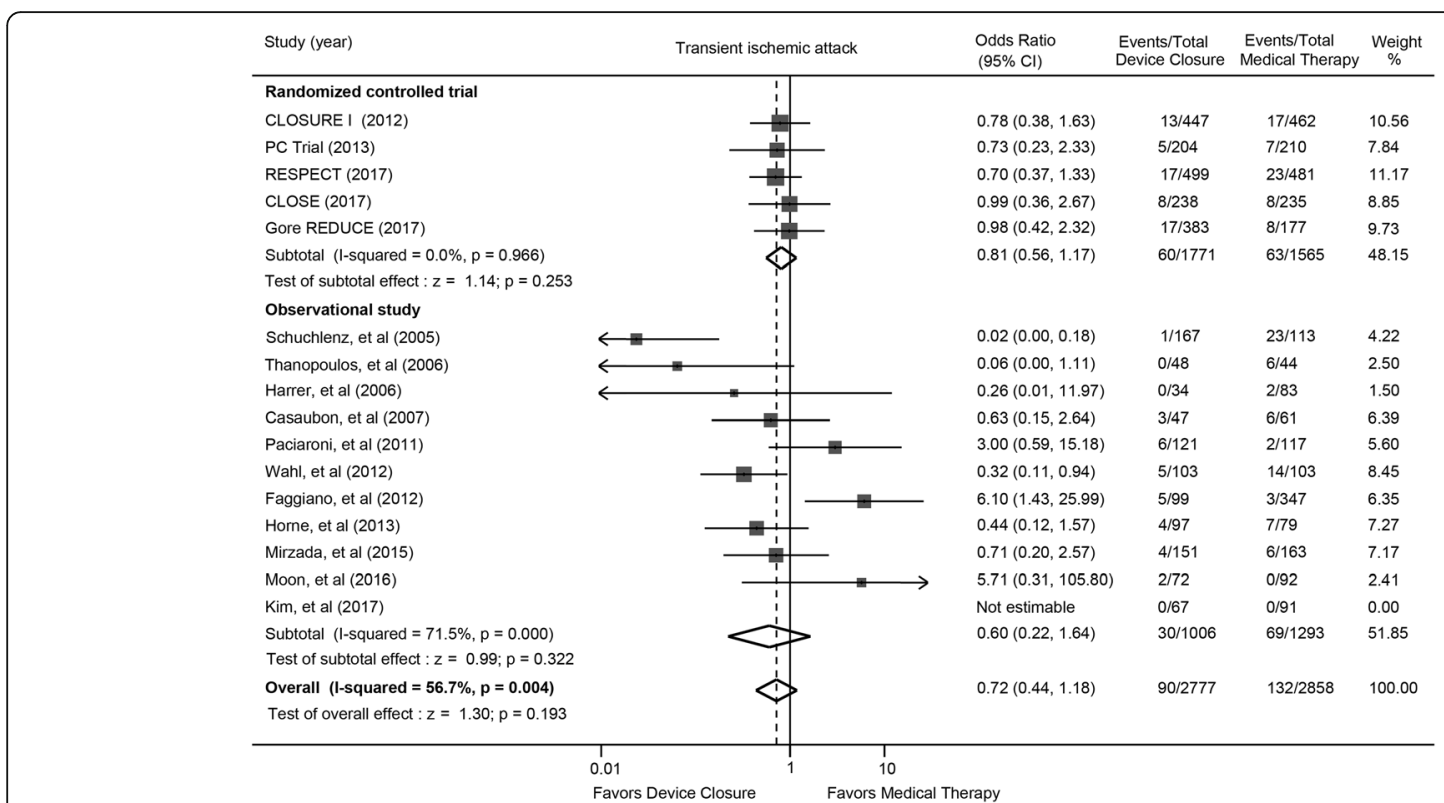

Fig. 3 Transient ischemic attack with device closure versus medical therapy. Gore CLOSURE I = Evaluation of the STARFlex Septal Closure System in Patients with a Stroke and/or Transient Ischemic Attack due to Presumed Paradoxical Embolism; CLOSE = the Patent Foramen Ovale Closure or Anticoagulants versus Antiplatelet Therapy to Prevent Stroke Recurrence; PC = Percutaneous Closure of Patent Foramen Ovale in Cryptogenic Embolism; REDUCE = Gore HELEX Septal Occluder and Antiplatelet Medical Management for Reduction of Recurrent Stroke or Imaging-Confirmed TIA in Patients with Patent Foramen Ovale; RESPECT = Randomized Evaluation of Recurrent Stroke Comparing PFO Closure to Established Current Standard of Care Treatment

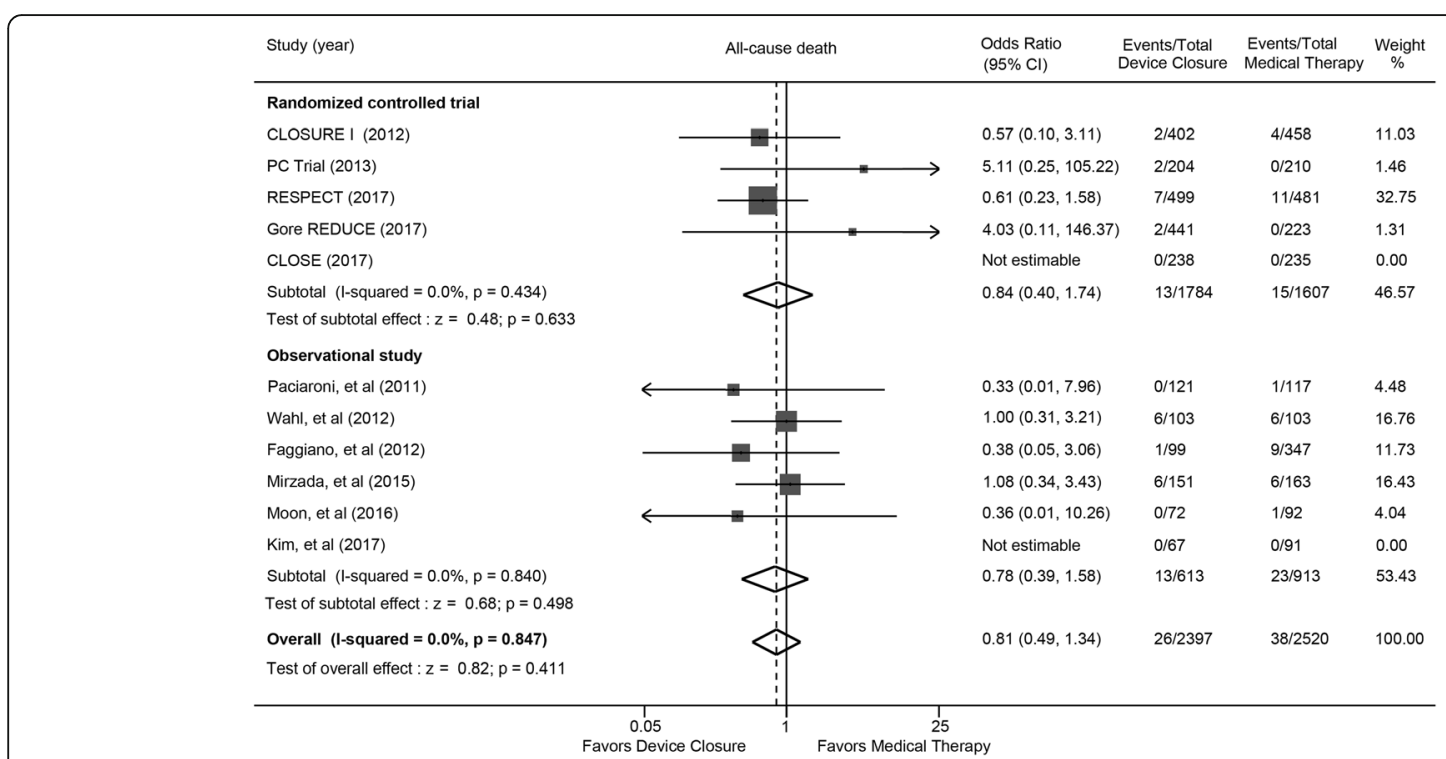

Fig. 4 All-cause death with device closure versus medical therapy. Gore CLOSURE I = Evaluation of the STARFlex Septal Closure System in Patients with a Stroke and/or Transient Ischemic Attack due to Presumed Paradoxical Embolism; CLOSE = the Patent Foramen Ovale Closure or Anticoagulants versus Antiplatelet Therapy to Prevent Stroke Recurrence; PC = Percutaneous Closure of Patent Foramen Ovale in Cryptogenic Embolism; REDUCE = Gore HELEX Septal Occluder and Antiplatelet Medical Management for Reduction of Recurrent Stroke or Imaging-Confirmed TIA in Patients with Patent Foramen Ovale; RESPECT = Randomized Evaluation of Recurrent Stroke Comparing PFO Closure to Established Current Standard of Care Treatment 


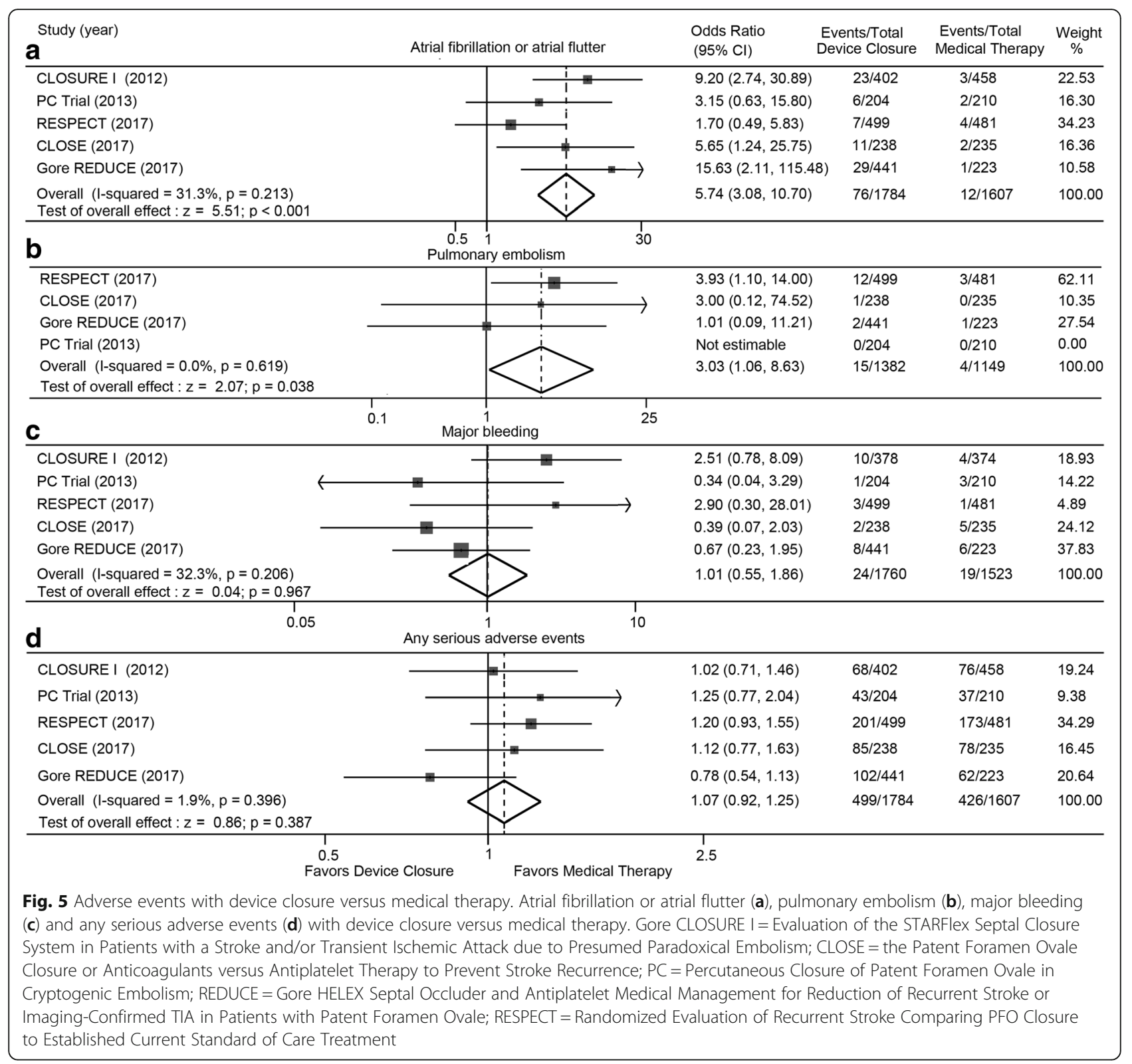

PFO [40]. However, there is a body of evidence not corroborating these findings. A comprehensive metaanalysis with individual participant data from 12 databases did not report a difference in composite outcome of recurrent stroke, TIA or death, or the individual outcome of stroke alone [41]. The very recently released interim analysis of the NAVIGATE ESUS trial, which compared novel oral anticoagulants rivaroxaban with aspirin in patients with cryptogenic embolic stroke, did not detect a difference in rate of stroke or systemic embolism after enrolling 7214 patients [42]. Also in our meta-regression analysis, no interaction was detected between these 2 medical treatment options with respect to the primary and secondary outcomes. As such, currently available data do not provide definite conclusions on whether antiplatelet or anticoagulation medications are superior for patients with a PFO and stroke [43].

In the setting of PFO and concurrent deep venous thrombosis (DVT) without cancer, in which patients are indicated to receive anticoagulant therapy (dabigatran, rivaroxaban, apixaban, or edoxaban over vitamin $\mathrm{K}$ antagonist), the most recent 2014 American Heart Association (AHA) and American Stroke Association guideline recommended that PFO closure might be considered, depending on the risk of recurrent DVT [44]. It should be noted that our observations were obtained on the basis that the vast majority of patients ( 98\%) did not have DVT, in which most patients received antiplatelet 
Table 2 GRADE assessment of confidence in estimates of effect in randomized trials

\begin{tabular}{|c|c|c|c|c|c|c|c|c|}
\hline Outcome & $\begin{array}{l}\text { No. of participants } \\
\text { (trials) }\end{array}$ & Risk of bias & Consistency & Directness & Precision & Publication bias & Quality & $\begin{array}{l}\text { Odds ratio } \\
(95 \% \mathrm{Cl})\end{array}$ \\
\hline $\begin{array}{l}\text { Composite } \\
\text { outcome }\end{array}$ & $2776(4)$ & $\begin{array}{l}\text { No serious } \\
\text { limitations }\end{array}$ & $\begin{array}{l}\text { No serious } \\
\text { limitations }\end{array}$ & $\begin{array}{l}\text { Serious } \\
\text { limitations }\end{array}$ & $\begin{array}{l}\text { No serious } \\
\text { limitations }\end{array}$ & Not detected & Moderate & $\begin{array}{l}0.62 \\
(0.44,0.88)\end{array}$ \\
\hline $\begin{array}{l}\text { Recurrent } \\
\text { ischemic stroke }\end{array}$ & $3440(5)$ & $\begin{array}{l}\text { No serious } \\
\text { limitations }\end{array}$ & $\begin{array}{l}\text { Serious } \\
\text { limitations }^{\dagger}\end{array}$ & $\begin{array}{l}\text { No serious } \\
\text { limitations }\end{array}$ & $\begin{array}{l}\text { No serious } \\
\text { limitations }\end{array}$ & Not detected & Moderate & $\begin{array}{l}0.41 \\
(0.19,0.89)\end{array}$ \\
\hline $\mathrm{TIA}$ & $3336(5)$ & $\begin{array}{l}\text { No serious } \\
\text { limitations }\end{array}$ & $\begin{array}{l}\text { No serious } \\
\text { limitations }\end{array}$ & $\begin{array}{l}\text { No serious } \\
\text { limitations }\end{array}$ & $\begin{array}{l}\text { Serious } \\
\text { limitations" }\end{array}$ & Not detected & Moderate & $\begin{array}{l}0.81 \\
(0.56,1.17)\end{array}$ \\
\hline All-cause death & 3391 (5) & $\begin{array}{l}\text { No serious } \\
\text { limitations }\end{array}$ & $\begin{array}{l}\text { No serious } \\
\text { limitations }\end{array}$ & $\begin{array}{l}\text { No serious } \\
\text { limitations }\end{array}$ & $\begin{array}{l}\text { Serious } \\
\text { limitations" }\end{array}$ & Not detected & Moderate & $\begin{array}{l}0.84 \\
(0.40,1.74)\end{array}$ \\
\hline $\begin{array}{l}\text { Atrial fibrillation } \\
\text { or atrial flutter }\end{array}$ & 3391 (5) & $\begin{array}{l}\text { No serious } \\
\text { limitations }\end{array}$ & $\begin{array}{l}\text { No serious } \\
\text { limitations }^{\ddagger}\end{array}$ & $\begin{array}{l}\text { No serious } \\
\text { limitations }\end{array}$ & $\begin{array}{l}\text { No serious } \\
\text { limitations }\end{array}$ & Not detected & High & $\begin{array}{l}5.74 \\
(3.08,10.70)\end{array}$ \\
\hline $\begin{array}{l}\text { Pulmonary } \\
\text { embolism }\end{array}$ & $2531(4)$ & $\begin{array}{l}\text { No serious } \\
\text { limitations }\end{array}$ & $\begin{array}{l}\text { No serious } \\
\text { limitations }\end{array}$ & $\begin{array}{l}\text { No serious } \\
\text { limitations }\end{array}$ & $\begin{array}{l}\text { Serious } \\
\text { limitations" }\end{array}$ & Not detected & Moderate & $\begin{array}{l}3.03 \\
(1.06,8.63)\end{array}$ \\
\hline Major bleeding & $3283(5)$ & $\begin{array}{l}\text { No serious } \\
\text { limitations }\end{array}$ & $\begin{array}{l}\text { No serious } \\
\text { limitations }^{\ddagger}\end{array}$ & $\begin{array}{l}\text { Serious } \\
\text { limitations }\end{array}$ & $\begin{array}{l}\text { Serious } \\
\text { limitations }\end{array}$ & Not detected & Low & $\begin{array}{l}1.01 \\
(0.55,1.86)\end{array}$ \\
\hline
\end{tabular}

GRADE Grading of Recommendations Assessment, Development and Evaluation, OR odds ratio, TIA transient ischemic attack

${ }^{\dagger}$ Moderate to substantial heterogeneity: $I^{2}=59 \%$

$\left.{ }^{\ddagger}\right|^{2}=31$ and $32 \%$ respectively. Did not downgrade for mild heterogeneity

${ }^{\S}$ Definitions of the composite outcome and major bleeding varied across trials. In 2 trials, peripheral embolism or systemic embolism was included in the definition of composite outcome

"95\% confidence interval $(\mathrm{Cl})$ suggests potential for benefit and harm. Low number of outcome events

therapy in the medical therapy. The American guidelines, however, did not recommend PFO closure in these set of patients (class III, level of evidence A). It is important to realize that the guideline was written when the current evidence was yet not available. Based on the updated evidence from randomized trials and our metaanalysis, PFO closure might be an alternative in young patients with PFO and cryptogenic stroke without DVT, particular in but not limited to those concomitant with the presence of an atrial septal aneurysm or large shunt size. Whether benefits of closure would be achieved in other subgroup populations awaits further study. It is important to take into account the benefits in reducing risks for stroke but also the harm in increasing pulmonary embolism.

There are several limitations in our study. First, most observational studies included in our meta-analysis were not adjusted for confounding factors. Second, definitions of the outcomes of interest were not identical across studies. Third, substantial heterogeneity was observed in several analyses. Fourth, results of meta-regression analyses and prespecified subgroup data can only be considered exploratory. Fifth, performance of different device cannot be performed. Finally, our findings cannot be generalized to patients older than 60 years of age.

\section{Conclusions}

Compared with medical therapy for the secondary prevention of cryptogenic stroke, our study showed moderate-quality evidence that PFO closure was associated with significantly lower incidence of the composite outcome of ischemic stroke, TIA, or all-cause death, which was mainly driven by lower risk for ischemic stroke. However, PFO closure increased the risks for atrial fibrillation or atrial flutter (high-quality evidence) and pulmonary embolism (moderate-quality evidence). The risks for TIA, all-cause death, and major bleeding were similar.

\section{Additional files}

Additional file 1: PRISMA 2009 Checklist. (DOCX 29 kb)

Additional file 2: Figure S1. Flow diagram of study selection. Table S1. Main inclusion and exclusion criteria of included randomized trials.

Table S2. Definitions of degree of shunting and atrial septal aneurysm in randomized trials. Table S3. Primary and secondary endpoints of included randomized trials. Table S4. Definitions of composite outcome, major bleeding, recurrent stroke and TIA in randomized trials. Table S5. Risk of bias of included randomized trials. Table S6. Study quality of included comparative observational studies using the Newcastle-Ottawa scale. Figure S2. The composite outcome of recurrent stroke, TIA and all-cause death with device closure versus medical therapy from randomized controlled trials and adjusted observational studies. Table S7. Subgroup analysis of the major outcomes based on study designs, number of patients and duration of follow-up. Table S8. Subgroup analysis of the composite outcome in randomized trials. Table S9. Subgroup analysis of recurrent ischemic stroke in randomized trials. Table S10. Meta-regression analysis in randomized trials exploring the potential for effect modification by multiple variables, including Moderate to severe PFO, atrial septal aneurysm, index event of stroke, and anticoagulation in medical treatment. (DOCX 594 kb)

\section{Abbreviations}

Cl: confidence interval; GRADE: Grading of Recommendations, Assessment, Development and Evaluation; OR: odds ratio; PFO: patent foramen ovale; $\mathrm{RCT}$ : randomized controlled trial; TIA: transient ischemic attack

\section{Acknowledgements}

None. 


\section{Funding}

This study was supported by the National Natural Science Foundation of China (NO. 81600312). The funders had no role in the study design, data collection and analysis, writing of the report, and decision to submit the article for publication.

\section{Availability of data and materials}

All data generated or analyzed during this study are included in this published article and its Additional file 1 and Additional file 2.

\section{Authors' contributions}

$X-L Z$ conceived the study, selected studies and extracted the data, analyzed and interpreted the data, and wrote the first draft of the manuscript. L-NK selected studies and extracted the data, analyzed and interpreted the data, and wrote the first draft of the manuscript. LW contributed to the study protocol and analyzed and interpreted the data. BX conceived the study, interpreted the data, and wrote the first draft of the manuscript. All authors read and approved the final manuscript.

\section{Ethics approval and consent to participate}

Not applicable.

\section{Consent for publication}

Not applicable.

\section{Competing interests}

The authors declare that they have no competing interests.

\section{Publisher's Note}

Springer Nature remains neutral with regard to jurisdictional claims in published maps and institutional affiliations.

Received: 22 January 2018 Accepted: 22 February 2018

Published online: 02 March 2018

\section{References}

1. Saver JL. Cryptogenic stroke. N Engl J Med. 2016;374:2065-74

2. Homma S, Messé SR, Rundek T, Sun YP, Franke J, Davidson K, Sievert H, Sacco RL, Di Tullio MR. Patent foramen ovale. Nat Rev Dis Primers. 2016;2:15086.

3. Alsheikh-Ali AA, Thaler DE, Kent DM. Patent foramen ovale in cryptogenic stroke: incidental or pathogenic? Stroke. 2009;40:2349-55.

4. Yaghi S, Bernstein RA, Passman R, Okin PM, Furie KL. Cryptogenic stroke: research and practice. Circ Res. 2017:120:527-40.

5. Furlan AJ, Reisman M, Massaro J, Mauri L, Adams H, Albers GW, et al. Closure or medical therapy for cryptogenic stroke with patent foramen ovale. N Engl J Med. 2012;366:991-9.

6. Meier B, Kalesan B, Mattle HP, Khattab AA, Hildick-Smith D, Dudek D, et al. Percutaneous closure of patent foramen ovale in cryptogenic embolism. N Engl J Med. 2013;368:1083-91.

7. Carroll JD, Saver JL, Thaler DE, Smalling RW, Berry S, MacDonald LA, Marks DS, Tirschwell DL. Closure of patent foramen ovale versus medical therapy after cryptogenic stroke. N Engl J Med. 2013;368:1092-100.

8. Kitsios GD, Thaler DE, Kent DM. Potentially large yet uncertain benefits: a meta-analysis of patent foramen ovale closure trials. Stroke. 2013:44:2640-3.

9. Li J, Liu J, Liu M, Zhang S, Hao Z, Zhang J, Zhang C. Closure versus medical therapy for preventing recurrent stroke in patients with patent foramen ovale and a history of cryptogenic stroke or transient ischemic attack. Cochrane Database Syst Rev. 2015;(9):CD009938. https://doi.org/10.1002/ 14651858.CD009938.pub2.

10. Stortecky S, Da Costa BR, Mattle HP, Carroll J, Hornung M, Sievert H, et al. Percutaneous closure of patent foramen ovale in patients with cryptogenic embolism: a network meta-analysis. Eur Heart J. 2015;36:120-8.

11. Kent DM, Dahabreh IJ, Ruthazer R, Furlan AJ, Reisman M, Carroll JD, et al. Device closure of patent foramen ovale after stroke: pooled analysis of completed randomized trials. J Am Coll Cardiol. 2016:67:907-17.

12. Moher D, Liberati A, Tetzlaff J, Altman DG. Preferred reporting items for systematic reviews and meta-analyses: the PRISMA statement. Ann Intern Med. 2009;151:264-9. W64

13. Higgins JPT, Altman DG, Sterne JAC. Assessing risk of bias in included studies. In: Higgins JPT, Green S, eds. Cochrane Handbook for Systematic Reviews of
Interventions. Version 5.1.0 [updated March 2011]. The Cochrane Collaboration; 2011. Accessed at http://handbook-5-1.cochrane.org/ on 5 Dec 2017.

14. Wells GA, Shea B, O'Connell D, Peterson J, Welch V, Losos M, et al. The Newcastle-Ottawa Scale (NOS) for assessing the quality of nonrandomised studies in meta-analyses. Ottawa, Ontario, Canada: Ottawa Hospital Research Institute; 2013. Accessed at www.ohri.ca/programs/clinical_epidemiology/ oxford.asp on 15 Dec 2015

15. Mantel N, Haenszel W. Statistical aspects of the analysis of data from retrospective studies of disease. J Natl Cancer Inst. 1959;22:719-48.

16. Higgins JP, Thompson SG, Deeks JJ, Altman DG. Measuring inconsistency in meta-analyses. BMJ. 2003;327:557-60.

17. Sweeting MJ, Sutton AJ, Lambert PC. What to add to nothing? Use and avoidance of continuity corrections in meta-analysis of sparse data. Stat Med. 2004;23:1351-75

18. Altman DG, Deeks JJ. Meta-analysis, Simpson's paradox, and the number needed to treat. BMC Med Res Methodol. 2002;2:3.

19. Cates CJ. Simpson's paradox and calculation of number needed to treat from meta-analysis. BMC Med Res Methodol. 2002;2:1.

20. Saver JL, Carroll JD, Thaler DE, Smalling RW, LA MD, Marks DS, Tirschwell DL. Long-term outcomes of patent foramen ovale closure or medical therapy after stroke. N Engl J Med. 2017;377:1022-32.

21. Mas JL, Derumeaux G, Guillon B, Massardier E, Hosseini H, Mechtouff L, et al. Patent foramen ovale closure or anticoagulation vs. antiplatelets after stroke. N Engl J Med. 2017;377:1011-21.

22. Søndergaard L, Kasner SE, Rhodes JF, Andersen G, Iversen HK, Nielsen-Kudsk

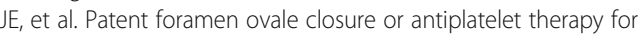
cryptogenic stroke. N Engl J Med. 2017;377:1033-42.

23. Wahl A, Jüni $P$, Mono ML, Kalesan B, Praz F, Geister L, et al. Long-term propensity score-matched comparison of percutaneous closure of patent foramen ovale with medical treatment after paradoxical embolism. Circulation. 2012;125:803-12

24. Alushi B, Biasco L, Orzan F, Omedé P, Sciuto F, Moretti C, et al. Patent foramen ovale treatment strategy: an Italian large prospective study. J Cardiovasc Med. 2014:15:761-8.

25. Pezzini A, Grassi M, Lodigiani C, Patella R, Gandolfo C, Zini A, et al. Propensity score-based analysis of percutaneous closure versus medical therapy in patients with cryptogenic stroke and patent foramen ovale: the IPSYS registry (Italian project on stroke in young adults). Circ Cardiovasc Interv. 2016;9

26. Moon J, Kang WC, Kim S, Oh PC, Park YM, Chung WJ, et al. Comparison of outcomes after device closure and medication alone in patients with patent foramen Ovale and cryptogenic stroke in Korean population. Yonsei Med J. 2016:57:621-5.

27. Thanopoulos BV, Dardas PD, Karanasios E, Mezilis N. Transcatheter closure versus medical therapy of patent foramen ovale and cryptogenic stroke. Catheter Cardiovasc Interv. 2006;68:741-6.

28. Casaubon L, McLaughlin P, Webb G, Yeo E, Merker D, Jaigobin C. Recurrent stroke/TIA in cryptogenic stroke patients with patent foramen ovale. Can J Neurol Sci. 2007;34:74-80.

29. Faggiano $P$, Frattini $S$, Piovesana $P$, Lorusso $R$, Chiari E, Scolari F, Padovani A Cas LD. Low cerebrovascular event rate in subjects with patent foramen ovale and different clinical presentations: results from a prospective non randomized study on a population including patients with and without patent foramen ovale closure. Int J Cardiol. 2012;156:47-52.

30. Harrer JU, Wessels T, Franke A, Lucas S, Berlit P, Klotzsch C. Stroke recurrence and its prevention in patients with patent foramen ovale. Can J Neurol Sci. 2006;33:39-47.

31. Horner S, Niederkorn $K$, Gattringer T, Furtner M, Topakian R, Lang W, Maier R, Gamillscheg A, Fazekas F. Management of right-to-left shunt in cryptogenic cerebrovascular disease: results from the observational Austrian paradoxical cerebral embolism trial (TACET) registry. J Neurol. 2013;260:260-7.

32. Kim M, Kim S, Moon J, Oh PC, Park YM, Shin DH, et al. Effect of patent foramen ovale closure for prevention on recurrent stroke or transient ischemic attack in selected patients with cryptogenic stroke. J Interv Cardiol. 2017. https://doi.org/ 10.1111/joic.12430.

33. Lee JY, Song JK, Song JM, Kang DH, Yun SC, Kang DW, Kwon SU, Kim JS Association between anatomic features of atrial septal abnormalities obtained by omni-plane transesophageal echocardiography and stroke recurrence in cryptogenic stroke patients with patent foramen ovale. Am J Cardiol. 2010;106:129-34

34. Mazzucco S, Bovi P, Carletti M, Tomelleri G, Golia G, Stegagno C, et al. A model of multi-disciplinary approach to the diagnosis and treatment of 
young patients with cryptogenic stroke and patent foramen ovale. Cardiol Young. 2012;22:327-34.

35. Mirzada N, Ladenvall P, Hansson PO, Eriksson P, Dellborg M. Recurrent stroke in patients with patent foramen ovale: an observational prospective study of percutaneous closure of PFO versus non-closure. Int J Cardiol. 2015;195:293-9.

36. Paciaroni M, Agnelli G, Bertolini A, Pezzini A, Padovani A, Caso V, et al. Risk of recurrent cerebrovascular events in patients with cryptogenic stroke or transient ischemic attack and patent foramen ovale: the FORI (foramen Ovale Registro Italiano) study. Cerebrovasc Dis. 2011;31:109-16.

37. Schuchlenz HW, Weihs W, Berghold A, Lechner A, Schmidt R. Secondary prevention after cryptogenic cerebrovascular events in patients with patent foramen ovale. Int J Cardiol. 2005;101:77-82.

38. Marfella R, Sasso FC, Siniscalchi M, Cirillo M, Paolisso P, Sardu C, et al. Brief episodes of silent atrial fibrillation predict clinical vascular brain disease in type 2 diabetic patients. J Am Coll Cardiol. 2013;62:525-30.

39. Rizzo MR, Sasso FC, Marfella R, Siniscalchi M, Paolisso P, Carbonara O, et al. Autonomic dysfunction is associated with brief episodes of atrial fibrillation in type 2 diabetes. J Diabetes Complicat. 2015;29:88-92.

40. Almekhlafi MA, Wilton SB, Rabi DM, Ghali WA, Lorenzetti DL, Hill MD. Recurrent cerebral ischemia in medically treated patent foramen ovale: a meta-analysis. Neurology. 2009;73:89-97.

41. Kent DM, Dahabreh IJ, Ruthazer R, Furlan AJ, Weimar C, Serena J, et al. Anticoagulant vs. antiplatelet therapy in patients with cryptogenic stroke and patent foramen ovale: an individual participant data meta-analysis. Eur Heart J. 2015:36:2381-9.

42. Neale T. Rivaroxaban trial in patients with embolic stroke of undetermined source stopped early. Available at https:/www.tctmd.com/news/rivaroxabantrial-patients-embolic-stroke-undetermined-source-stopped-early. Accessed 10 Oct 2017.

43. Messe SR, Gronseth G, Kent DM, Kizer JR, Homma S, Rosterman L, Kasner SE Practice advisory: recurrent stroke with patent foramen ovale (update of practice parameter): report of the guideline development, dissemination, and implementation Subcommittee of the American Academy of neurology. Neurology. 2016;87:815-21.

44. Kernan WN, Ovbiagele B, Black HR, Bravata DM, Chimowitz MI, Ezekowitz $M D$, et al. Guidelines for the prevention of stroke in patients with stroke and transient ischemic attack: a guideline for healthcare professionals from the American Heart Association/American Stroke Association. Stroke. 2014; 45:2160-236.

\section{Submit your next manuscript to BioMed Central and we will help you at every step:}

- We accept pre-submission inquiries

- Our selector tool helps you to find the most relevant journal

- We provide round the clock customer support

- Convenient online submission

- Thorough peer review

- Inclusion in PubMed and all major indexing services

- Maximum visibility for your research

Submit your manuscript at www.biomedcentral.com/submit

C) Biomed Central 